CINEMA

\title{
"Chris MARKER: O DISCRETO ARTESÃO DO TEMPO E DA MEMÓRIA FOI TAMBÉM UM GÊNIO DA HUMILDADE"
}

Christian François Bouche-Villeneuve morreu em Paris no dia 30 de julho - 91 anos completos após seu nascimento, em 29 de julho de 1921. No final dos anos 1940, Bouche-Villeneuve assumiu um pseudônimo pronunciável na maioria das línguas: Chris Marker. Em entrevista com Guy Gauthier para Image et Son (no. 162-162, junho de 1963, p.52-53), Alain Resnais pontuava: "Existe uma teoria que circula, e com um certo fundamento, segundo a qual Chris Marker seria um extraterrestre. Ele tem aparência humana, mas a verdade é que vem do futuro ou de um outro planeta." Escritor, fotógrafo, cineasta, artista multimídia - um bricoleur de imagens, como ele mesmo gostava de se definir -, Marker foi um pioneiro do cinema experimental, do cinéma vérité (embora preferisse o rótulo "ciné, ma vérité"), do filme-ensaio e das artes do vídeo, entre outras modalidades fronteiriças e desafiadoras das convenções estabelecidas. Viajante inveterado, ávido por imagens dos mais diversos cantos do planeta, Marker aparece escondendo o rosto em Tokyo-Ga (1985), de Wim Wenders, flagrado num café da capital japonesa. Avesso a badalaçôes, não dava muitas entrevistas e evitava ser fotografado. A marca que deixa na história do cinema, bem como sua influência sobre outros cineastas, é inversamente proporcional à sua vontade de aparecer.

A obra de Marker se constitui de uma variedade de trabalhos nos mais diversos suportes e formatos: livros, instalações, mídias digitais e mais de 50 filmes. Como denominador comum de uma carreira tão multifacetada, sobressai o interesse pela natureza do tempo e o fascínio pela memória. Marker estreou no cinema com o documentário Olympia 52, sobre os Jogos Olímpicos de Helsinque, na Finlândia, em 1952. No ano seguinte, o artista escreveu o roteiro da narração para o documentário Estátuas também morrem (Les statues meurent aussi, 1953), o qual dirigiu junto com Alain Resnais. Este filme ganhou o prêmio Jean Vigo e foi censurado por mais de 10 anos na França, em virtude de seu conteúdo político.

AS MARCAS DE MARKER O refinamento do recurso à voz-over (a "voz da imagem”) revelou-se um traço distintivo no cinema de Marker. Esse tipo de narração - a "voz de Deus" - está em filmes do início de sua carreira, como Domingo em Pequim (Dimanche à Pekin, 1956) ou Cartas da Sibéria (Lettre de Sibérie, 1957). O documentário Cartas da Sibéria propõe uma fascinante reflexão so- bre as relações interditas entre imagem e palavra, reproduzindo uma mesma sequência sob comentários absolutamente distintos. A imagem - assim provoca Marker - assume um estatuto ambíguo e fugidio, sujeito a diferentes impostaçôes ideológicas. Cartas da Sibéria suscitou o crítico André Bazin a pensar num "ensaio sob forma de filme", e desse em momento em diante ganha visibilidade o formato do "filme-tese".

A voz-over está presente também no que talvez seja o mais célebre dos filmes de Marker, o curta-metragem La jetée (1962), definido pelo diretor como "a história de um homem marcado por uma imagem da infância" ("Ceci est l'histoire d'un homme marquépar une image d'enfance"). Ficção científica sobre viagem no tempo, $\mathrm{La}$ jetée foi realizado após a filmagem de Le joli mai (1963), documentário que buscava revelar, por meio de entrevistas nas ruas de Paris, o inconsciente coletivo francês marcado pela guerra na Argélia. Construído a partir de imagens estáticas, com exceção de um único plano com movimento, La jetée ilustra o fascínio de Marker pela obra de Alfred Hitchcock, em especial Um corpo que cai (Vertigo, 1958), citado, entre outros momentos, na cena em que o viajante do tempo explica à amada o decorrer das eras recorrendo à árvore seccionada-em 1997, Marker apresentava o CD-ROM Immemory (Paris: Yves Gevaert Editeur/Centre Georges Pompidou), obra interativa voltada ao tema da memória e outra homenagem a Hitchcock. Immemmory oferece também um denso inventário da obra do artista e suas influências. Se o cinema permite uma sofistica- 


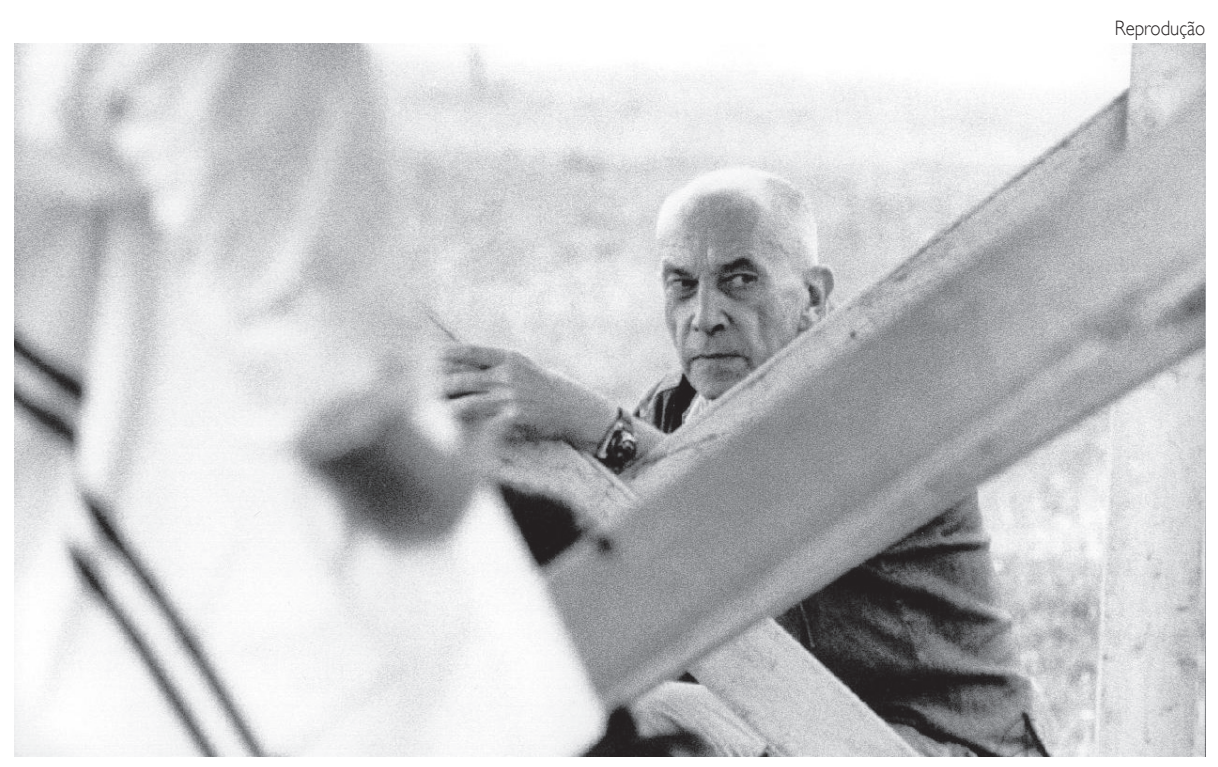

Em 91 anos de vida, Chris Marker deixa uma obra com mais de 50 filmes, em que sobressai seu interesse pela natureza do tempo e fascínio pela memória

da manipulação do tempo através da montagem, La jetée demonstra que mesmo imagens estáticas podem ser criativamente submetidas ao fluxo do tempo, em favor de uma macronarrativa. Com isso, o filme trata de um conteúdo posto em constante debate através de sua forma. A propósito de La jetée, Raymond Bellour explica, em Entre-Imagens (Campinas: Papirus, 1997), "por que esse filme de ficção (e até mesmo de ficção científica) pode parecer indispensável numa seleção de caráter documentário (...)" (p. 170). Bellour observa também que “(...) não é o movimento que define o cinema de forma mais profunda (...), mas o tempo" (1997, p. 92). Como no documentário clássico, a narração de Jean Negroni em La jetée guia o espectador a determinadas conclusões ou "descobertas morais". Quando a viagem no tempo começa a se efetuar, o narrador instiga nosso afeto pela realidade ao comentar o aparecimento de ima- gens "verdadeiras": "um quarto de dormir verdadeiro", "crianças verdadeiras", "pássaros verdadeiros", "gatos verdadeiros" e "sepulturas". La jetté atingiu o status de filme cult e sua influência e valor cinematográfico são inversamente proporcionais à sua concisão e singeleza. $\mathrm{O}$ filme de Marker foi a base para Os doze macacos (Twelve monkeys, 1995), longa-metragem hollywoodiano dirigido por Terry Gilliam, e inspirou homenagens como La vie d'un chien (2005), de John Harden, curta vencedor no Festival de Cannes. Sobre essa pérola na carreira de Marker, Terry Gilliam comentou: "O filme brilhante, funciona num nível musical-é como se ouvíssemos música. A montagem é a mais extraordinária que jamais vi, porque é um ritmo que está sendo estabelecido, e a voz, a narrativa, você está lidando com poesia neste ponto."

Em 1967, Marker fundava o coletivo Slon (Société pour le Lancement funciona porque é tão tecnicamente des Oeuvres Nouvelles) - e que também significa "elefante", em russo. Entre os filmes do Slon estão À bientôt, j'espère (1968), sobre greve em indústria têxtil francesa, e $O$ sexto lado do Pentágono (La sixième face du Pentagone, 1968), sobre marcha antimilitarista no Pentágono. O monumental Longe do Vietnã (Loin du Vietnam, 1967) sobressai como um dos mais ambiciosos projetos do grupo. Filme-protesto contra a Guerra do Vietnã, conta com a participação de Alain Resnais, Jean-Luc Godard, Agnès Varda e outros cineastas, além do próprio Marker.

TRAÇOS DE BRASIL Embora muito pouco conhecido no Brasil, Marker não ignorou a história recente da América Latina em sua carreira. $\mathrm{Va}$ mos falar do Brasil: torturas (On vous parle du Brésil: tortures, 1969), documentário curto, de 20 minutos, enfoca crimes da ditadura militar brasileira. Carlos Marighella, personagem da história brasileira recente, também estimulou Marker a rodar outro capítulo de seu exame audiovisual do país, Vamos falar do Brasil: Carlos Marighella (On vous parle du Brésil: Carlos Marighella), documentário igualmente curto, porém não menos incisivo. A sangrenta ditadura de Allende também é examinada em On vous parle du Chili: ce que disait Allende (1973).

Numa fase mais adiantada de sua carreira, Marker dirigiu Sem Sol (Sans Soleil), uma de suas obras-primas - mescla de filme etnográfico, ensaio filosófico e poesia. Sem Solfoi lançado no Brasil pela Versátil, num único DVD que reúne também sua outra obra-prima, o já citado La je- 
tée. Sem Sol viaja da Islândia à Guiné-Bissau, e finalmente ao Japão, país pelo qual Marker desenvolveu afeto e interesse especiais - daí seu "flagrante" no filme de Wim Wenders, e a homenagem no distrito de Golden Gai, em Tóquio, num bar chamado "La jetée".

O interesse pela obra de outros cineastas também sempre foi um traço norteador na obra de Marker. Raros diretores foram tão atentos e perspicazes com respeito ao trabalho de colegas. Além de Hitchcock, Alexander Medvedkin, Andrei Tarkovsky e Akira Kurosawa também atraíram a atenção de Marker em filmes como O trem prossegue (Le train em marche, 1973) e Oúltimobolchevique (Letombeau d'Alexandre, 1993), sobre Medvedkin; Um dia na vida de Andrei Arsenevich (One day in the life of Andrei Arenevich, 2000), sobre Tarkovski, e A.K. (1985), sobre os bastidores de Ran (1985), de Kurosawa.

O caráter fronteiriço e ambivalente, a metalinguagem e o teor político
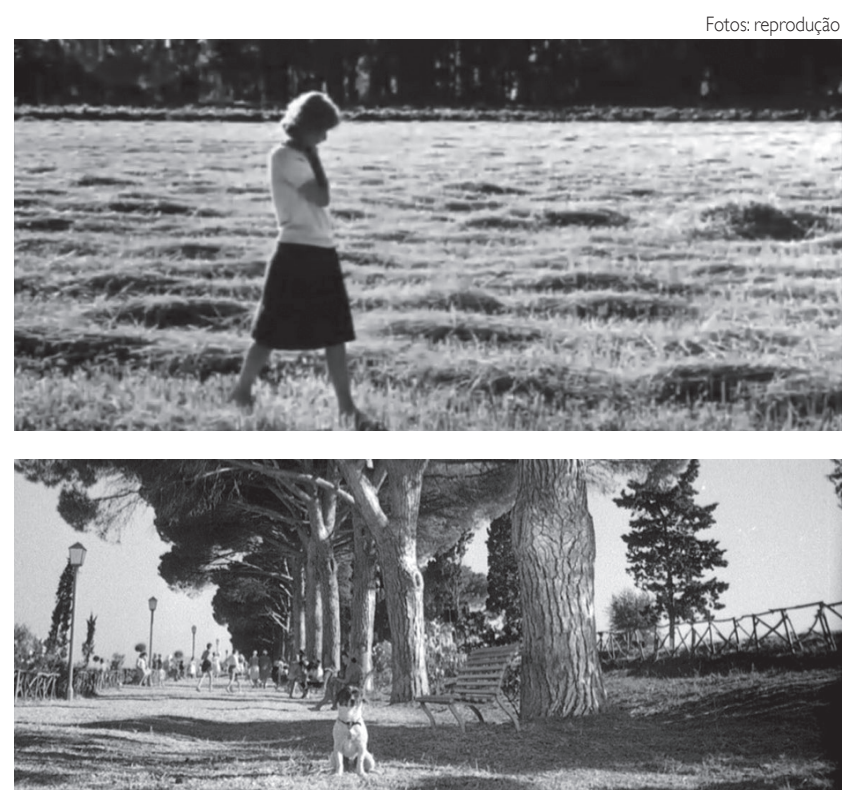

Com La jetée, atinge o status de cult, influenciando gerações foram elementos constantes na obra de Marker. Entre seus últimos trabalhos estão a instalação Filme silencioso (1995) e o longa-metragem Level five (1997), misto de documentário e ficção científica inspirado em eventos durante a Segunda Guerra Mundial, na ilha de Okinawa.

Aos 80 anos, Marker continuava a criar. Um de seus últimos trabalhos foi uma brevíssima história do cinema, encomendada por ocasião do quinquagésimo aniversário do Festival de Cinema de Viena, em outubro deste ano. $\mathrm{O}$ artista ainda trabalhava em instalações e em obras no ambiente virtual do Second Life. Aliás, uma das raras (e últimas) entrevistas de Marker foi realizada através dessa interface (http://www. lesinrocks.com/2008/04/29/cinema/la-seconde-vie-de-chris-marker-1151546/). Sob o pseudônimo de Sergei Murasaki ele fala sobre as vantagens do desenvolvimento da informática, chamando a atenção para a possibilidade de se realizar um filme completamente sozinho, com os "próprios dez dedos”. Assim surgiu o vídeo Chats perchés (2004), o qual Marker pôde gravar, fazer o DVD e vender no mercado de Saint-Blaise, diretamente do produtor ao consumidor, sem nenhum apoio ou intervenção de terceiros - uma concretização do sonho de Marx, segundo Marker.
AUTORIA Em 1997, o diretor comentou: "O processo de fazer filmes em comunhão consigo mesmo, o modo como um pintor ou escritor trabalham, não precisam mais ser agora exclusivamente experimentais. Contrariamente ao que pensam as pessoas, usar a primeira pessoa em filmes tende a ser um sinal de humildade: tudo o que tenho a oferecer sou eu mesmo". Ao modelo clássico de se enunciar cinema, à transparência e estratégia do meganarrador fílmico que a tudo organiza como um deus - porém sem deixar vestígios de sua manipulação -, Marker opõe a instância do homem diante de seu filme, do realizador que se assume enquanto o arauto de mensagens extáticas, poéticas, políticas ou oníricas.

Para maiores informações sobre Chris Marker, vale lembrar que, no final de 1993, a publicação francesa Images Documentaires (http://www. imagesdocumentaires.fr/Chris-Marker.html) lançou um número especialmente dedicado a ele, com artigos de François Niney, Régis Debray e do próprio Marker, entre outros autores. Em português, o livro $O$ bestiário de Chris Marker (1986), publicado pela Livros Horizonte, de Portugal, traz uma variedade de textos sobre o cineasta francês, por diferentes autores. É tempo de retrospectivas, mostras e exposições da obra de Marker no Brasil. Seu Immemmory não foi lançado no país, seus trabalhos em multimídia e instalaçôes são ainda mais desconhecidos por aqui do que seus filmes. E uma mostra de seus filmes poderia reavivar o interesse pelo ensaio audiovisual debruçado sobre a história.

Alfredo Suppia e Julia Milward 